\title{
Pattern and Clinical Presentation of Endometriosis Among the Indigenous Africans
}

\author{
Joseph Wanyoike Gichuhi ${ }^{1,}$, Julius Ogengo $^{2}$, Peter Gichangi ${ }^{2}$ \\ ${ }^{1}$ Department of Obstetrics \& Gynaecology, University of Nairobi, Nairobi, Kenya \\ ${ }^{2}$ Department of Anatomy, University of Nairobi, Nairobi, Kenya
}

Email address:

drjoewanyoike@yahoo.co.uk (J. W. Gichuhi)

${ }^{*}$ Corresponding author

To cite this article:

Joseph Wanyoike Gichuhi, Julius Ogengo, Peter Gichangi. Pattern and Clinical Presentation of Endometriosis Among the Indigenous Africans. Journal of Gynecology and Obstetrics. Vol. 9, No. 3, 2021, pp. 92-99. doi: 10.11648/j.jgo.20210903.17

Received: May 31, 2021; Accepted: June 15, 2021; Published: June 28, 2021

\begin{abstract}
Background: Endometriosis is enigmatic clinical entity which is described as the existence of the endometrial tissue external of the uterine cavity. Endometriosis constitutes a serious health issue due to its high affliction of $10 \%$ in reproductive age women and its clinical manifestation of infertility and chronic pelvic pain. Despite of years of research, the causative factor and understanding of ambidextrous endometriosis pathology remains elusive, perplex and disconnected. Worldwide, there is clear documentation of prevalence of endometriosis in the development countries, however, the prevalence of endometriosis in most of black Africa is unknown. The current perspective is that indigenous African are rarely affected by endometriosis. Objective: To determine the prevalence, pattern and clinical presentation of endometriosis in indigenous African women with the primary outcome measure being the prevalence of laparoscopic visually diagnosed, histologically confirmed endometriosis and clinical presentation. Methodology: This was a prospective analytical cross-selection study in 2 hospitals in Nairobi city, Kenya. The sample size was 443 women and the duration of the study was from March 2018 to March 2021. The inclusion criteria was women aged at least 18 years up to 49 years undergoing laparoscopic surgery and willing to take part in the study. The patient's history, clinical and laparoscopic findings and histological diagnosis were recorded and analysed using Social SPSS version 22.0. Results: The mean age of the 443 patients recruited was 33 years. The prevalence of histological confirmed endometriosis in indigenous Africans was 6.8\%. Laparoscopic visualization diagnosis had a positive predictive value of 39\%. Dysmenorrhoea, chronic pelvic pain scale 8-10 and dyspareunia were significant symptoms of endometriosis $\mathrm{P}<0.001$. Nulliparous patients significantly had a risk of having endometriosis $\mathrm{p}<0.001$. The patients with menarche at 13 years and below had a significant risk of having endometriosis $p=0.001$. Physical findings on clinical examination of adnexal tenderness and findings of nodules in the pouch of Douglas were significant in relation to endometriosis $\mathrm{p}<0.001$. The most common site of the histological endometriosis implants were on the Pouch of Douglas $(30 \%)$ and the most common form of endometriosis was superficial (43\%). Conclusion: The prevalence of endometriosis in Indigenous Africa is $6.8 \%$. Laparoscopic visualization diagnosis had low a positive predictive value of $39 \%$. Nulliparity, menarche at the age of 13 and below, dysmenorrhoea, chronic pelvic pain scale 8-10 and dyspareunia were significantly associated with endometriosis. The most common site for endometriosis is the of Pouch of Douglas whilst the most common form of endometriosis was superficial.
\end{abstract}

Keywords: Endometriosis, Prevalence, Clinical Presentation, Laparoscopy, Indigenous Africa

\section{Introduction}

Endometriosis, is a female reproductive disorder, described as existence of endometriotic glands and stroma outside endometrial cavity, mainly in the pelvic peritoneum, ovary and rectovaginal septum. Endometriosis afflicts 6\%-10\% of women and its symptomatology encompasses mainly chronic pelvic pain, dysmenorrhoea, dyspareunia and infertility and hence its' one of the most frequent gynaecological ailments [1]. Endometriosis prevalence in women with chronic pelvic pain and infertility, is as high as 
$35 \%-\% 50 \%$ in both [2]. In developed countries, there is explicit literature on the prevalence of endometriosis, however, in the developing countries there is scanty documentation [3]. Racial and social economic status factors in prevalence of endometriosis have not been addressed comprehensively by the current research and indeed has been neglected. Despite of years of research, the causative factor and understanding of the ambidextrous endometriosis pathology remains elusive, perplex and disconnected. [4]. Endometriosis constitutes a serious health issue due to its high affliction of $10 \%$ in reproductive age women and its clinical manifestation of infertility and chronic pelvic pain. [2, $5,6]$. Worldwide, there is clear documentation of prevalence of endometriosis in the development countries, however there is paucity of data on prevalence of endometriosis in Black Africa. [3]. The current perspective is that indigenous African is rarely affected by endometriosis. By definition the Indigenous African woman is the one living and born in Africa. [3]. In Black Africa the prevalence of endometriosis is not defined and laparoscopy surgery the gold standard for the diagnosis of endometriosis is rarely performed [3)]. The clinical appearance and locality of endometriosis is variable from one individual to another, and its clinical manifestation is divided into 3 categories; superficial peritoneal endometriosis, ovarian endometrioma and deep infiltrating endometriosis (DIE) [7-9]. Umbilical endometriosis which presents with occasional pain and bleeding has been associated with indigenous Africans [10] Endometriotic superficial peritoneal lesions are variable; classic - blue-black (considered 'diagnostic') and non-classic or subtle-clear or white, yellowish brown, red like lesions have been illustrated $[12,13]$.

In African indigenous woman in Nigeria, the endometriosis prevalence was $4.3 \%$ and $8.2 \%$ in laparotomy and hysterectomy specimen tissue [7, 8]. In laparoscopy, the visualization of endometriosis with no histological authentication was reported to be $48.1 \%$ in university college, Ibadan, Nigeria [14]. Currently there is a notion that an African-women is hardly inflicted with endometriosis. [3, 4]. Early marriage with subsequent multiple pregnancies and breastfeeding and increased incidence of pelvic inflammatory disease have been postulated as the cause of low prevalence of endometriosis in Indigenous Africans [15]. The incidence of endometriosis is anticipated to increase with the westernization of lifestyle and change in social economic status of the indigenous African woman. Laparoscopic visualization of endometriosis with histological confirmation is the gold standard for the diagnosis of endometriosis and has revolutionized the management of this disease. $[5,16]$. The presumption low prevalence of endometriosis in black Africa could be due to diagnostic technique; lack of adequate laparoscopy amenities and lack of distinct training in the African gynaecologist could be a factor [3]. It is important to note that no African study has primarily been designed for determination of endometriosis as the primary outcome using the diagnostic laparoscopic visualization with histological confirmation of the disease. The understanding of endometriosis prevalence and the clinical pattern is critically essential in endogenous African woman in view of the significant morbidity and public health complexities of this condition.

\section{Objective}

To determine the prevalence, pattern and clinical presentation of endometriosis among indigenous African women.

\section{Method}

This was an analytical cross-selection study whose primary outcome measure is the prevalence, pattern and clinical presentation of laparoscopic visually diagnosed and histologically confirmed endometriosis in indigenous African woman. The study was undertaken in 2 purposively selected hospitals across Nairobi city to ensure ownership and varying levels of speciality. The sites were Kenyatta National Hospital and Nairobi hospital in Nairobi city, Kenya. The study was reviewed and proved by the Kenyan ethical authority (Kenyatta National Hospital/University of Nairobi Ethics Research Committee) with respect to scientific content and compliance with applicable research and human subjects' regulations. The study population was indigenous African women aged $18-49$ years undergoing laparoscopic surgery in any of the two participating hospitals and all patients that meet the inclusion criteria were included in the study until the estimated sample size is achieved.

The respondents were informed about the study, its objectives, risks and benefits. The willing participants, were requested to provide written consent. The patients were reviewed pre- operatively for the history, clinical presentations and investigations. Operatively, Examination Under Anaesthesia (EUA) was performed and any endometriotic lesion noted, hysteroscopy and laparoscopy was performed and the clinical findings noted. Wong /Baker face pain rating scale indicated below was used in pain assessment in this study [17]. The anatomical location and staging of the endometriosis was documented. The extent of the endometriosis was described using revised America Society for reproductive Medicine (Revised ASM) [11]. Subtle lesion that might represent endometriosis were excised even if endometriosis was not suspected. One to four biopsies were taken from each patient. Histological confirmation of endometriosis was done by staining samples with haematoxylin and eosin. The structured questionnaire was completed by the clinician preparing the patient for surgery while completeness and follow-up for any missing information was done by the principle investigator. All data obtained from the questionnaire was verified and had double entered into a computer using Microsoft Access database. The data was analysed using Social SPSS version 22.0. The chi-square and logistic regression were used to determine the predictors of endometriosis among women undergoing laparoscopic surgery. $\mathrm{P}$ value of $<0.05$ was considered significant. 


\section{Results}

Table 1. Socio Demographic Characteristics and Endometriosis Status $(n=443)$.

\begin{tabular}{|c|c|c|c|c|c|}
\hline Characteristics & Total, n (\%) & Endometriosis, n (\%) & No Endometriosis, n (\%) & OR $(95 \% \mathrm{CI})$ & P-value \\
\hline \multicolumn{6}{|l|}{ Age } \\
\hline Mean & 33.0 & 30.4 & 33.2 & - & 0.011 \\
\hline Median & 32.0 & 30.5 & 33.0 & - & 0.020 \\
\hline Range & [18-49] & {$[18-46]$} & [18-49] & - & - \\
\hline$\leq 24$ & $29(6.5)$ & $5(16.7)$ & $24(5.8)$ & 1 & 0.039 \\
\hline $25-29$ & $108(24.4)$ & $6(20.0)$ & $102(24.7)$ & $3.5(1.0-12.6)$ & 0.146 \\
\hline $30-34$ & $132(29.8)$ & $11(20.0)$ & $121(29.3)$ & $2.3(0.7-7.3)$ & 0.010 \\
\hline$\geq 35$ & $174(39.3)$ & $8(26.7)$ & $166(40.2)$ & $4.3(1.3-14.3)$ & \\
\hline \multicolumn{6}{|l|}{ Education Level } \\
\hline None & $40(2.1)$ & $8(1.2)$ & $32(2.5)$ & 1 & \\
\hline Primary & $443(23.0)$ & $148(23.1)$ & $295(23.0)$ & $0.5(0.2-1.1)$ & 0.082 \\
\hline Secondary & $942(49.0)$ & $323(50.4)$ & $619(48.3)$ & $0.5(0.2-1.1)$ & 0.061 \\
\hline Tertiary & $322(16.7)$ & $107(16.7)$ & $215(16.8)$ & $0.5(0.2-1.1)$ & 0.091 \\
\hline Missing & $176(9.2)$ & $55(8.6)$ & $121(9.4)$ & - & - \\
\hline Married & $357(80.6)$ & $18(60.0)$ & $339(82.1)$ & 1 & \\
\hline Separated & $33(7.4)$ & $1(3.3)$ & $32(7.7)$ & $1.7(0.2-13.1)$ & 0.607 \\
\hline Single & $51(11.5)$ & $11(36.7)$ & $40(9.7)$ & $0.2(0.1-0.4)$ & $<0.001$ \\
\hline Windowed & $2(0.5)$ & - & $2(0.2)$ & - & - \\
\hline \multicolumn{6}{|l|}{ Occupation } \\
\hline Employed & $271(61.2)$ & $20(66.7)$ & $251(60.8)$ & 1 & \\
\hline Self-Employed & $92(20.8)$ & $3(10.0)$ & $89(21.5)$ & $2.3(0.7-8.1)$ & 0.161 \\
\hline Not-Employed & $80(18.1)$ & $7(23.3)$ & $73(17.7)$ & $0.8(0.3-2.0)$ & 0.686 \\
\hline
\end{tabular}

Table 2. Gynaecological History and Endometriosis Status ( $n=443)$.

\begin{tabular}{|c|c|c|c|c|c|}
\hline Characteristics & Total, n (\%) & Endometriosis, n (\%) & No Endometriosis, n (\%) & OR $(95 \%$ CI $)$ & P-value \\
\hline \multicolumn{6}{|l|}{ Parity } \\
\hline Mean & 1 & 0 & 1 & - & 0.001 \\
\hline Median & 0 & 0 & 1 & - & 0.001 \\
\hline Range & {$[0-8]$} & {$[0-2]$} & {$[0-8]$} & - & - \\
\hline Zero & $228(51.5)$ & $24(80.0)$ & $204(49.4)$ & 1 & 0.191 \\
\hline One & $60(13.5)$ & $3(10.0)$ & $57(13.8)$ & $2.2(0.6-7.7)$ & 0.146 \\
\hline Two & $65(14.7)$ & $3(10.0)$ & $62(15.0)$ & $2.4(0.7-8.3)$ & - \\
\hline$\geq$ Three & $90(20.3)$ & - & $90(21.8)$ & - & \\
\hline \multicolumn{6}{|l|}{ No. of Abortions } \\
\hline Mean & 0 & 0 & 0 & - & 0.198 \\
\hline Median & 0 & 0 & 0 & - & 0.309 \\
\hline Range & {$[0-5]$} & {$[0-1]$} & {$[0-5]$} & - & - \\
\hline None & $356(80.4)$ & $26(86.7)$ & $330(79.9)$ & 1 & 0.419 \\
\hline $1-3$ & $83(18.7)$ & $4(13.3)$ & $79(19.1)$ & $1.6(0.5-4.6)$ & - \\
\hline \multicolumn{6}{|c|}{ Age at Menarche (Yrs.) Mean } \\
\hline Median & 13.0 & 12.4 & 13 & - & 0.001 \\
\hline Range & 13.0 & 12.5 & 13 & - & 0.001 \\
\hline $10-12$ & $11-21$ & $11-14$ & $11-21$ & - & 0.002 \\
\hline $13-15$ & $116(26.2)$ & $15(50.0)$ & $101(24.5)$ & 1 & \\
\hline \multirow[t]{2}{*}{$16+$} & $323(72.9)$ & $15(50.0)$ & $308(74.6)$ & $3.0(1.4-6.5)$ & \\
\hline & $4(0.9)$ & - & $4(1.0)$ & - & \\
\hline \multicolumn{6}{|c|}{ Duration of Flow Mean } \\
\hline Median & 5 & 6 & 5 & - & 0.442 \\
\hline Range & 5 & 6 & 5 & - & 0.835 \\
\hline $0-3$ & $0-10$ & $4-10$ & $0-10$ & - & - \\
\hline $4-7$ & $30(6.8)$ & 0 & $30(7.3)$ & - & - \\
\hline \multirow[t]{2}{*}{$8+$} & $349(78.8)$ & $28(93.3)$ & $321(77.7)$ & 1 & 0.165 \\
\hline & $64(14.4)$ & $2(6.7)$ & $62(15.0)$ & $2.7(0.6-11.6)$ & \\
\hline Menorrhagia & $81(18.3)$ & $2(6.7)$ & 79 (19.1) & $0.3(0.1-1.3)$ & 0.088 \\
\hline
\end{tabular}


Table 3. Physical finding on Examination and Endometriosis Status ( $n=443)$.

\begin{tabular}{|c|c|c|c|c|c|}
\hline Characteristics & Total, n (\%) & Endometriosis, n (\%) & No Endometriosis, n (\%) & OR $(95 \%$ CI $)$ & P-value \\
\hline Lower Abdominal Tenderness & $116(26.2)$ & $14(46.7)$ & $102(24.7)$ & $2.7(1.3-5.7)$ & 0.008 \\
\hline Pelvic Mass & $93(21.0)$ & $2(6.7)$ & $91(22.0)$ & $0.3(0.1-1.1)$ & 0.046 \\
\hline Adnexal Mass & $85(19.2)$ & $8(26.7)$ & $77(18.6)$ & $1.6(0.7-3.7)$ & 0.281 \\
\hline Adnexal Tenderness & $71(16.0)$ & $13(43.3)$ & $58(14.0)$ & $4.7(2.2-10.1)$ & $<0.001$ \\
\hline Extroverted Uterus & $26(5.9)$ & $3(10.0)$ & $23(5.6)$ & $1.9(0.5-6.7)$ & 0.319 \\
\hline Nodules P. O. D & $6(1.4)$ & $3(10.0)$ & $3(0.7)$ & $15.2(2.9-78.8)$ & $<0.001$ \\
\hline Normal Findings & $167(37.7)$ & $8(26.7)$ & $159(38.5)$ & $0.6(0.3-1.3)$ & 0.196 \\
\hline
\end{tabular}

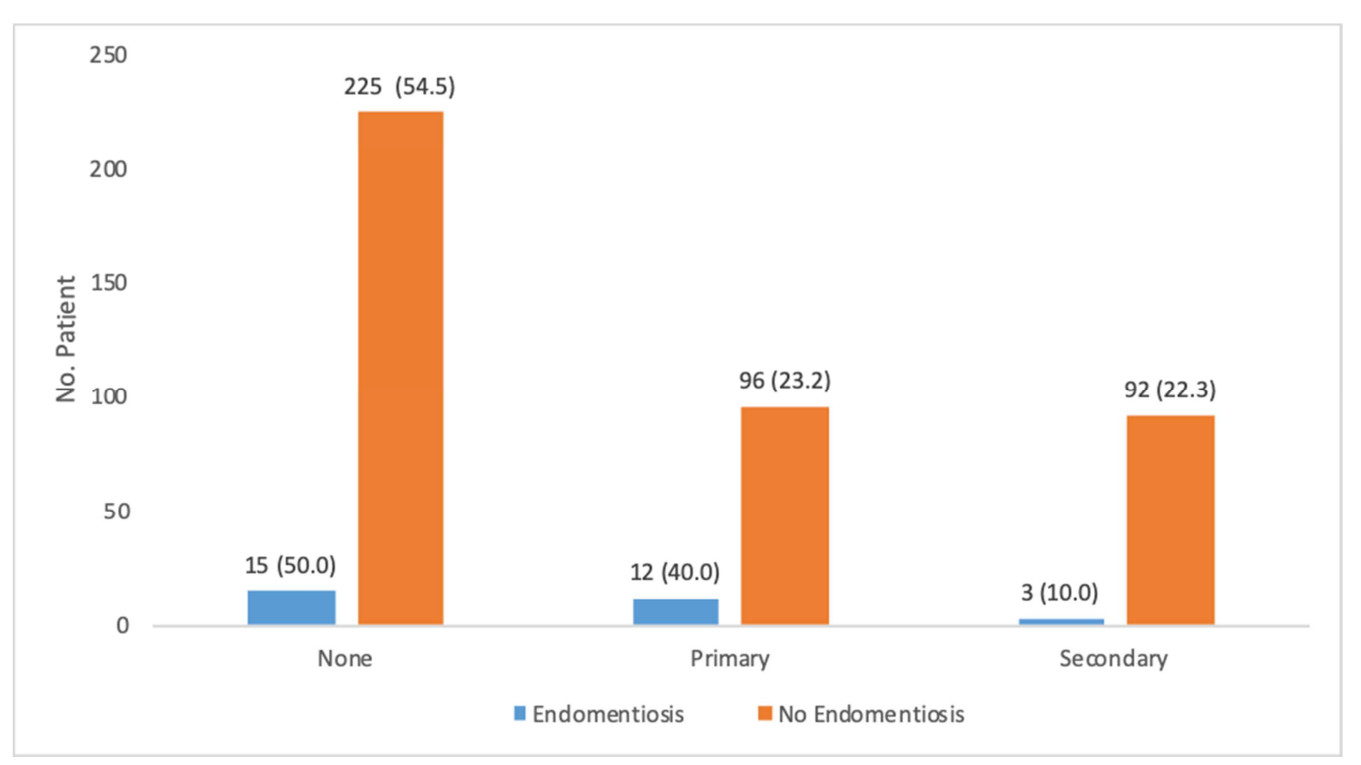

Figure 1. Association between Infertility and Endometriosis Status (n=443).

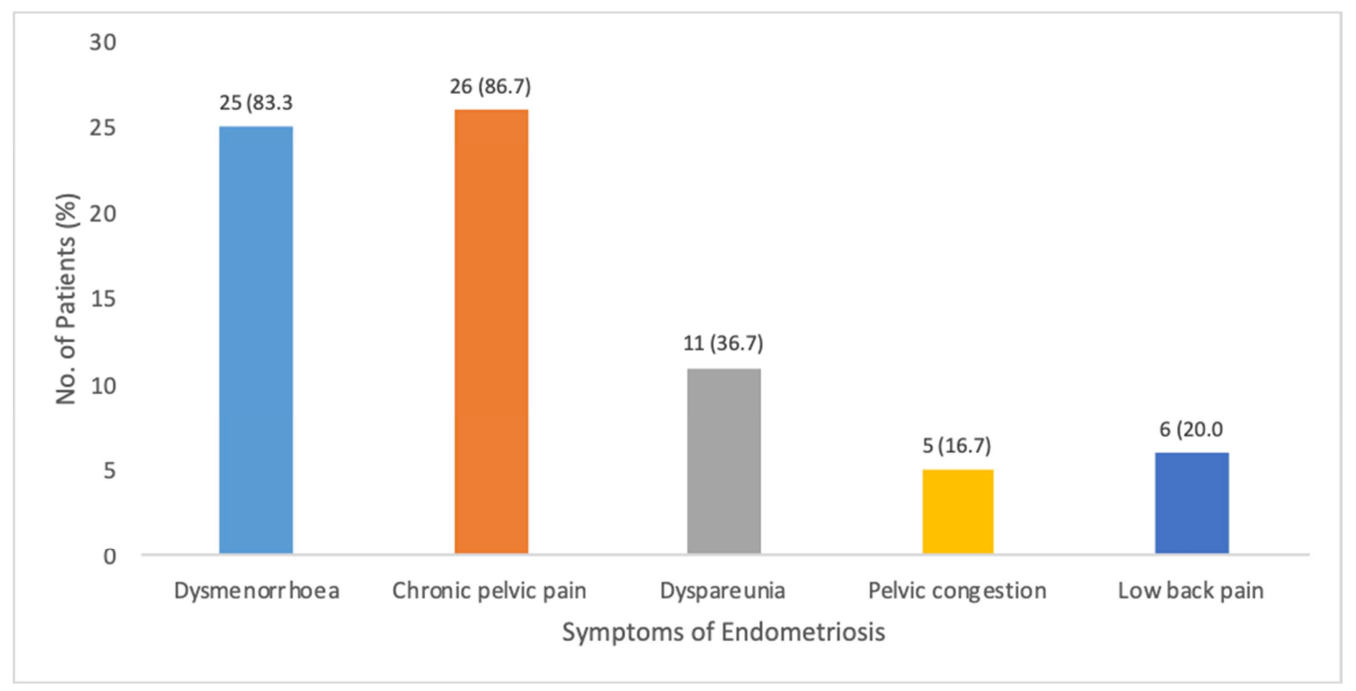

Figure 2. Symptoms of Endometriosis $(n=30)$.

Table 4. Signs of Endometriosis $(n=30)$.

\begin{tabular}{lll}
\hline Signs of Endometriosis & $\mathbf{n}$ & \% \\
\hline Puckered blue-black & 6 & 20.0 \\
Powder-burned appearance & 10 & 33.3 \\
Subtle (Popular, Glandular, vesicular) & 3 & 10.0 \\
Haemorrhagic (Red vesicular or Flame-like) & 8 & 26.7 \\
Fibrotic lesions (White to black pigmented). & 9 & 30.0 \\
Chocolate cyst/endometrioma. & 8 & 26.7 \\
Deep Infiltrating Endometriosis & 8 & 26.7 \\
Extra pelvic & 2 & 6.7 \\
\hline
\end{tabular}


Table 5. Anatomical site of Endometriosis $(n=30)$.

\begin{tabular}{lll}
\hline & $\mathbf{n}$ & \% \\
\hline Anatomic site of endometriosis & & 6.7 \\
Anterior uterine & 2 & 3.3 \\
Extra pelvic site & 1 & 3.3 \\
Gut & 1 & 6.7 \\
Bilateral ovaries & 2 & 6.7 \\
Posterior uterine & 2 & 30.0 \\
Pouch of Douglas & 9 & 20.0 \\
Utero-sacral ligaments & 6 & 23.3 \\
Unilateral ovary & 7 & \\
\hline
\end{tabular}

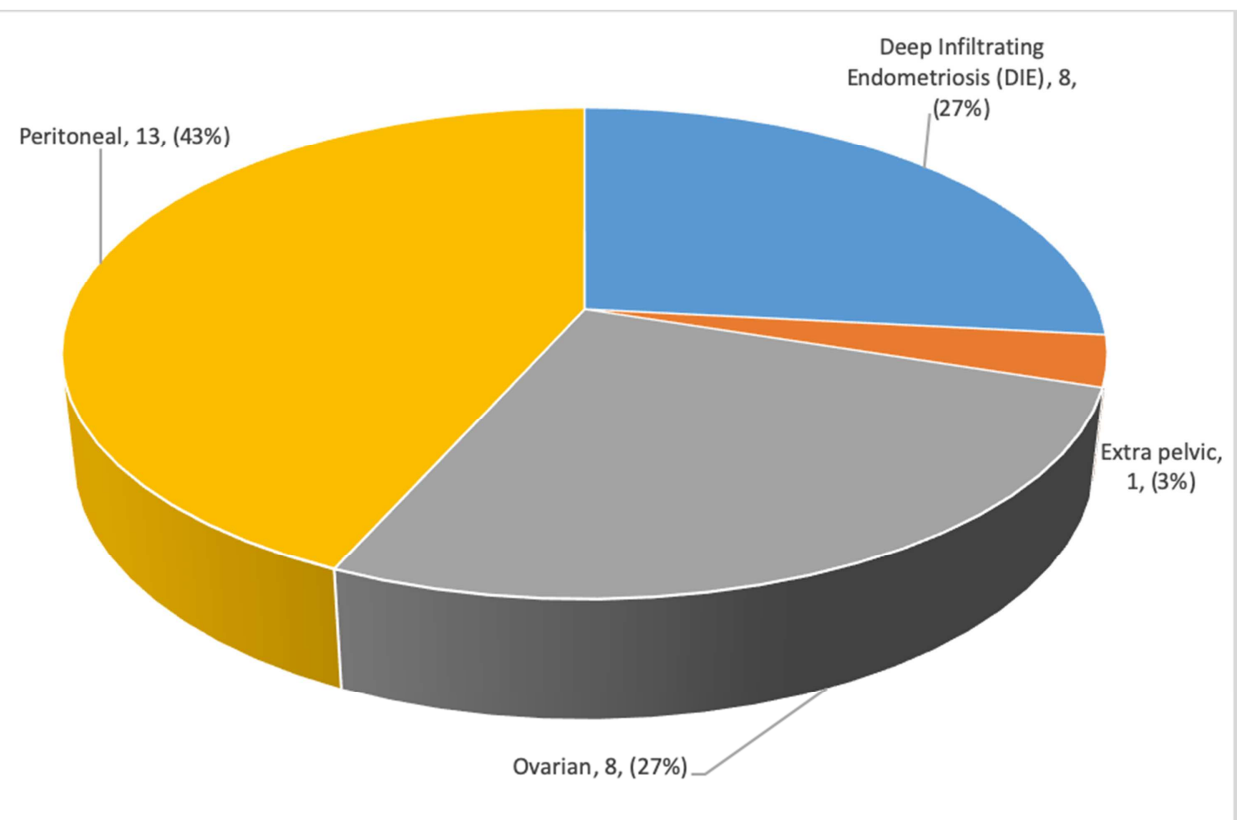

Figure 3. Classification of Endometriosis Status ( $n=30)$.

Table 6. Histological findings on laparoscopic biopsies. $N=443$.

\begin{tabular}{lll}
\hline & $\mathbf{n}$ & $\mathbf{\%}$ \\
\hline Adenomyosis & 8 & 1.8 \\
Appendicitis & 5 & 1.1 \\
Cervical dysplasia & 1 & .2 \\
Clinical endometriosis but histologically no endometriosis & 24 & 5.4 \\
Confirmed histological endometriosis & 30 & 6.8 \\
Ectopic pregnancy & 4 & .9 \\
Endometrial hyperplasia & 1 & .2 \\
Fallopian tubes & 23 & 5.2 \\
Myoma & 88 & 19.9 \\
No pathology & 196 & 44.2 \\
Ovarian cyst & 45 & 10.2 \\
Ovarian malignancy & 4 & .9 \\
Teratoma & 5 & 1.1 \\
\hline
\end{tabular}

Table 7. Symptoms vs Endometriosis Status ( $n=443)$.

\begin{tabular}{llllll}
\hline Characteristics & Total, $\mathbf{n}(\%)$ & Endometriosis, $\mathbf{n}(\%)$ & No Endometriosis, $\mathbf{n}(\mathbf{\%})$ & OR (95\% CI) & P-value \\
\hline Dysmenorrhea & $95(21.4)$ & $25(83.3)$ & $70(16.9)$ & $24.5(9.1-66.2)$ & $<0.001$ \\
$\begin{array}{l}\text { Chronic Pelvic Pain } \\
\text { Scale of Pain }\end{array}$ & $152(34.3)$ & $26(86.7)$ & $126(30.5)$ & $14.8(5.1-43.3)$ & $<0.001$ \\
0 & & & $6(4.8)$ & 1 & 0.146 \\
$1-3$ & $6(4.0)$ & 0 & $63(50.8)$ & $0.4(0.1-1.4)$ & $<0.001$ \\
$4-7$ & $68(45.3)$ & $5(19.2)$ & $49(39.5)$ & $0.01(0.0-0.2)$ & \\
$8-10$ & $58(38.7)$ & $9(34.6)$ & $6(4.8)$ & $5.3(2.3-11.8)$ & $<0.001$ \\
Dyspareunia & $18(12.0)$ & $12(46.2)$ & $41(9.9)$ & $1.1(0.4-3.1)$ & 0.807 \\
Pelvic Congestion & $52(11.7)$ & $11(36.7)$ & $62(15.0)$ & $1.6(0.6-4.2)$ & 0.306 \\
Low Back Pain & $67(15.1)$ & $5(16.7)$ & $55(13.3)$ & & \\
\hline
\end{tabular}


Table 8. Infertility vs Endometriosis Status ( $n=443)$.

\begin{tabular}{|c|c|c|c|c|c|}
\hline Characteristics & Total, n (\%) & Endometriosis, n (\%) & No Endometriosis, n (\%) & OR $(95 \%$ CI) & P-value \\
\hline \multicolumn{6}{|l|}{ Infertility } \\
\hline None & $240(54.2)$ & $15(50.0)$ & $225(54.5)$ & & \\
\hline Primary & $108(24.4)$ & $12(40.0)$ & $96(32.2)$ & 1 & \\
\hline Secondary & $95(21.4)$ & $3(10.0)$ & $92(22.3)$ & $3.8(1.0-14.0)$ & 0.031 \\
\hline Overall, & $443(100.0)$ & $30(100.0)$ & $413(100.0)$ & & \\
\hline
\end{tabular}

Table 9. Chronic pelvic pain and stage of Endometriosis.

\begin{tabular}{|c|c|c|c|c|}
\hline \multirow[b]{2}{*}{ Stage of endometriosis } & \multicolumn{2}{|c|}{ Chronic Pelvic pain } & \multicolumn{2}{|c|}{ No chronic pelvic pain } \\
\hline & No. & $\%$ & No. & $\%$ \\
\hline Superficial & 6 & 27.2 & 4 & 50 \\
\hline Ovarian Endometrioma & 8 & 36.4 & 3 & 37.5 \\
\hline Deep Infiltrating endometriosis & 8 & 36.4 & 1 & $12 \mathrm{i} 5$ \\
\hline Total & 22 & 100 & 8 & 100 \\
\hline
\end{tabular}

Table 10. Infertility and Stage of Endometriosis.

\begin{tabular}{lllll}
\hline & Infertility & & No Infertility \\
\hline & No. & \% & No. \\
\hline Stage of endometriosis & & & & \\
Superficial & 3 & 20.0 & 9 & \\
Ovarian Endometrioma & 7 & 47.7 & 4 & 60.0 \\
Deep Infiltrating endometriosis & 5 & 33.3 & 2 & 15 \\
Total & 15 & 100 & 13.3 & 100 \\
\hline
\end{tabular}

Table 11. Histological findings $n=443$.

\begin{tabular}{lll}
\hline & NO & \% \\
\hline Confirmed histological endometriosis & 30 & 6.8 \\
Clinical endometriosis by visualization & 77 & 17 \\
\hline
\end{tabular}

\section{Discussion}

The mean age of the all patients in the study was 33 years and there was no statistical difference between the patient with endometriosis and those without. The single women were more likely to have endometriosis $(p<0.001)$, while married and separated women were not predisposed. The women's occupation and the level of education had no effect on the occurrence of endometriosis.

The prevalence of histological confirmed endometriosis was $6.8 \%$, however the most common pathology was myoma (19.9\%) and $44.2 \%$ of the patients had no pathology detected. Endometriosis clinical diagnosed by visualization were 77 $(17.4 \%)$ and out of this only $30(6.8 \%)$ were histologically confirmed. Laparoscopic visualization diagnosis had low a positive predictive value of $39 \%$. The prevalence of endometriosis has been speculated to be as high as $10 \%$ of the women of reproductive age, however, this study did not concur [18]. The findings in this study are consisted with a study in Nigeria, where endometriosis in 2 communities of Igbo and Hause/Fulani was found to be $4.3 \%$ and $8.2 \%$ respectively from hysterectomy and laparotomy specimen, which had histologically confirmation of endometriosis [12, 15]. This study was not consisted with a Nigerian study in Ibadan where the prevalence of endometriosis was found to be $48.8 \%$ with the diagnosis criteria for endometriosis being laparoscopic visualization without histological confirmation [14]. Furthermore, this study showed the prevalence of endometriosis with laparoscopic visualization only to be $17.4 \%$. This study was not consisted with Chapmans laparoscopic studies, where he found prevalence of endometriosis with histological confirmation to be $21 \%$ in women who had had pelvic inflammatory disease treatment in African American women. [19].

Physical findings on clinical examination of lower abdominal tenderness, pelvic mass and extroverted uterus were not significantly related to the endometriosis, however, adnexal tenderness and findings of nodules in the pouch of Douglas were significant in relation to endometriosis, $\mathrm{p}<0.001$.

Nulliparous patients significantly had a risk of having endometriosis $\quad \mathrm{p}<0.001$. Prolonged uninterrupted menstruation like in nulliparous or in menorrhagic women or menstruation with less than 27 days cycle and usage of tampons may predispose to development of endometriosis $[20,21$. The number of abortions did not significantly influence the occurrence of endometriosis. Menorrhagia had no significant correlation with endometriosis in this study $\mathrm{P}=0.088$. However, epidemiological studies have demonstrated that short menstrual cycle and prolonged menstruation are risk factors in the development of endometriosis [22-24].

The symptoms of dysmenorrhoea, Chronic pelvic pain scale 8-10 and dyspareunia were significant findings in endometriosis $\mathrm{p}<0.001$. There is a positive relationship between endometriosis with chronic pelvic pain and dysmenorrhoea have been associated with increased risk of 
endometriosis [25].

The patients with menarche at 13 years and below had a significant risk of having endometriosis $p=0.001$ than those with menarche above the age of 13 years. Literature shows a positive relationship between early menarche and endometriosis [26].

Patients with endometriosis had 50\% infertility, however, there was no correlation between infertility and endometriosis $\mathrm{p}=0.031$, whilst the prevalence of infertility in women without endometriosis was $42 \%$. In 2 studies, the prevalence of infertility in laparoscopic diagnosed endometriosis was found to be $38.5 \%$ and $25-40 \%$ compared to fertile one of $5.2 \%$ and $0.5-5 \%$ respectively $[27,28]$. Other literature, have shown occurrence of $5-50 \%$ of infertility in endometriosis; it has also been documented that infertility is 6-8 times more likely to occur in endometriosis than in fertile women $[29,30]$. In this study, patients with endometrioma $(47.7 \%)$ and deep infiltrating endometriosis (33.0\%) were more like to have infertility than those with superficial endometriosis $(20.0 \%)$. The above finds are consisted with literature which shows that infertility in women with endometriosis is most likely to occur in the advanced stage of the disease [15].

The sites of the endometriosis implants were on the Pouch of Douglas (30\%), Unilateral ovaries $(23.3 \%)$, uterosacral $(20 \%)$, posterior uterus $(6.7 \%)$, Bilateral ovaries $(6.7 \%)$, Anterior uterus (6.7\%), Gut (3.3\%) and extra pelvic site (3.3\%). These findings are consisted with the literature that endometriosis occurs more frequently on structures adjacent to the fallopian tube ostia, that is the pouch of Douglas, utero-sacral ligaments and the ovaries, offering credence to the hypothesis of retrograde menstruation [27]. Endometrial implants are also more likely to attach themselves in the posterior uterus in the African American rather than anteriorly [31].

The majority of the histological confirmed endometriosis were superficial endometriosis (43\%), with ovarian and deep infiltrating endometrioma each having $27 \%$ and extra pelvic endometriosis havening $2 \%$. The most common form of presentation in superficial endometriosis was powder-burned appearance (33\%) followed by fibrotic lesions (30\%), puckered blue-black (20\%), subtle (10\%) whilst endometrioma and deep infiltrating endometriosis accounted for $26.7 \%$ with extra pelvic endometriosis being $2 \%$.

\section{Conclusion}

The histological confirmed endometriosis for the study was $6.8 \%$. Laparoscopic visualization diagnosis had low a positive predictive value of $39 \%$. Dysmenorrhoea, chronic pelvic pain scale 8-10 and dyspareunia were significant symptoms of endometriosis. Nulliparous patients significantly had a risk of having endometriosis $\mathrm{p}<0.001$. The patients with menarche at 13 years and below had a significant risk of having endometriosis $p=0.001$. The common sites of the histological confirmed endometriosis implants were on the Pouch of Douglas and were superficial endometriosis.

\section{References}

[1] Burney R O, Giudice L C. Pathogenesis and pathophysiology of Endometriosis. Fert. Steril. 2012; 98: 511-519.

[2] C. Meuleman, B. Vandenabeele, S. Fieuwsc, C Spiessens, D Tiiermann, T D'Hooghe High prevalence of endometriosis in infertile women with normal ovulation and normaspermic partners. Fertil. Steril. 2009; 92: 68-74.

[3] Kyema CM, Mwenda JW, Machoki J. A Mihalyi, P Simsa, DC Chai, T M D'Hooghe Endometriosis in African women. Women's Health. 2007; 3: 629-635.

[4] Ozkan S, Murk W, Arici A. Endometriosis and Infertility: Epidemiology and evidence based treatments. Ann. N. Y. Acad. Sci. 2008; 1127: 92-100.

[5] Sasson IE, Taylor HS. Stem cells and the pathogenesis of endometriosis. Ann. N. Y. acad. Sci. 2008; 1127: 106-115.

[6] Harkki P, Tiitnen A, Ylikorkala O. Endometriosis and assisted reproduction techniques. Ann. N. Y. Acad. Sci. 2010; 1205: 207-213.

[7] Osefo J., Okeke B. Endometriosis: Incidence among the Igbos of Nigeria. Int. J. Obstet. Gynaecol. 1989; 30: 349-53.

[8] Ekwempu CC, Harrison KK. Endometriosis among the Hausa/Fulani population of Nigeria. Trop. Geogr. Med. 1979; 31: 201-205.

[9] Fawole AO, Bello FA, Ogubonde O, OduKogbe AO, Nkwocha GC, Nnoham, KE, Zondervan KT, Akintan A, Abdus-Salam RA, Okunlola MA. Endometriosis and associated symptoms among Nigerian women. Int. J. Gynecol Obstet. 2015; 130: 190-194.

[10] Thacher TD, Nwana EJC, Karshima JA. Extrapelvic Endometriosis in Nigeria. Int. J. Gynaecol. Obstet. 1 997; 57: 57-58.

[11] American Society for Reproductive Medicine (ASRM). Revised American Society for reproductive medicine classification of endometriosis. Fertil. Steril. 2006; 67: 817821.

[12] Eskenazi B, M L Warner. Epidemiology of endometriosis. Obstet. Gynecol. Clin. N. Amer. 1997; 24: 2.

[13] Chatman D. Endometriosis in the Black Woman. Am. J. Obstet. Gynecol. 1976; 125: 987 -989.

[14] Cramer DW, Wilson E, Stillman RJ, Berger MJ, Beslisle S, Sciff I, Albrecht A, Gibson M, Stadel BV, Schoenbaum SC The relation of endometriosis to menstrual characteristics, smoking and exercise. JAMA 986; 355: 1904-1908.

[15] Ajosa S. The Prevalence of Endometriosis in Premenstrual Women Undergoing Gynaecological Surgery. Clin. Exp. Obstet. Gynaecol. 1994; 21: 195-197.

[16] Naegle CM, Bell TA, Purdie DM et al. Relative weight at ages 10 and 16 and risk of endometriosis: a case-controlled analysis. Hum. Reprod. 2009; 24: 1501-1506.

[17] Sourial S, Tempest N, Hapangamana DK. Theories on the pathogenesis of Endometriosis. Int. J. Reprod. Med. 2014; 179515 . 
[18] Houston DE Incidence of pelvic endometriosis in Rochester, Minonnesota. J. Epidemiol. 1987; 125: 959-969.

[19] Shade GH, Lane M, Diamond MP. Endometriosis in the African -American woman - racially, a different entity? Gyecol. Surg. 2012; 9: 59-62.

[20] Regina F, Pain assessment: the cornerstone to optimal pain management. Proc (Bayl Univ Med) 2000: 13: 236-239.

[21] Brosens I, Donnez J, Benagiodo G. Improving the Classification of Endometriosis. Hum. Reprod. 1993; 8: 17921795 .

[22] Koninckx PR, Ooster LD, D’Hooghe T, Meulman C. Deeply Infiltrating Endometriosis Is a Disease Whereas Mild Endometriosis Could Be Considered a Non-Disease. Ann. N. Y. Acad. Sci. 1994; 734: 333-341.

[23] Nisolle M, donnez J. Peritoneal Endometriosis, Ovarian Endometriosis and Adenomyotic Nodules of the Rectovaginal Septum and Three Different Entities. Fert Steril 1997; 68: 585-596.

[24] Albea RB, Sinervo K, Fisher DT. Laparoscopic excision of lesion suggestive of endometriosis or otherwise a typical in appearance: relationship between visual findings and final histological diagnosis. J. Minim. Invasive. gynecol 2008; 15: 32-37.

[25] Martin DC, Hubert GD, Vander Z et al. Laparoscopic Appearances of Peritoneal Endometriosis. Fertil. Steril. 1989; 51: 63-67.

[26] Cramer DW, Mismer SA. The epidemiology of endometriosis. Ann. N. Y. Acad. Sci. 2002: 955: 396-406.

[27] Verkauf BS, Incidence, symptoms, and signs of endometriosis in fertile and infertile women. J. Fla. Med. Assoc. 1987; 74: 671-675.

[28] Arumugam K, Lim JM. Menstrual characteristics associated with endometriosis. Br. J. Obstet. Gynecol. 1997; 104: 948950 .

[29] Vercelli P, De Giorgi O, Aime G et al. Menstrual characteristic in women with and without endometriosis. Obstet. Gynecol. 1997; 90: 264-268.

[30] Olive DL. Henderson DY. Endometriosis and Mullerian Anomalies. Obstet Gynaecol 1987; 69, 412.

[31] Motarrass R, Rodiquez F, Pijoun JI. Epidemiology of Endometriosis in Infertile Women. Fertil. Steril. 1995; 63: 34-38. 